\title{
Efeitos do heme livre na fibrinólise: um estudo in vitro e revisão da literatura
}

\author{
Vanessa M Tani* 1, Bidossessi Wilfried Hounkpe ${ }^{1}$, Beatriz Martinelli ${ }^{2}$, Silmara Lima Montalvão ${ }^{2}$, Vanessa \\ Araújo Gomes da Costa1, Erich V De Paula ${ }^{1}{ }^{2}$. ${ }^{1}$ Faculdade de Ciências Médicas da Unicamp, ${ }^{2}$ Centro de \\ Hematologia e Hemoterapia da Unicamp.
}

\section{Resumo}

O papel do heme livre em doenças hemoliticas não é totalmente compreendido, apresentando divergências entre seu papel pró e hipocoagulante. Também sabemos pouco sobre seu efeito no sistema fibrinolítico. Por isso, neste projeto, através da união de dados de dois projetos anteriores utilizandos métodos funcionais, pudemos aprofundar o papel do heme livre sobre a fibrinólise.

\section{Palavras-chave:}

Fibrinólise, heme, métodos funcionais

\section{Introdução}

O heme livre pode se comportar como uma molécula próinflamatória ou DAMP (padrão molecular associado ao perigo) ${ }^{1}$, contribuindo para o estado protrombótico, porém, também contribui para um estado de hipocoagulabilidade, reduzindo os níveis dos fatores de coagulação $\mathrm{V}$ e $\mathrm{VIII}^{2}$, prolongando TP e TTPA $^{3,4}$. No entanto pouco se sabe sobre o efeito do heme na fibrinólise. Dessa maneira, através da fusão de dados de dois projetos anteriores utilizando o tempo de lise do coágulo (TLC) e tromboelastometria (TEM) avaliamos o efeito do heme na fibrinólise.

\section{Métodos e resultados}

A

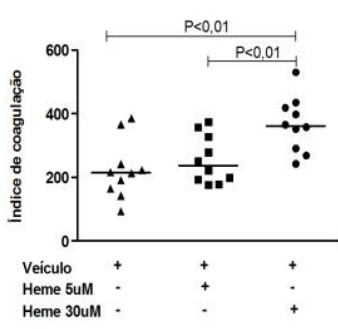

B

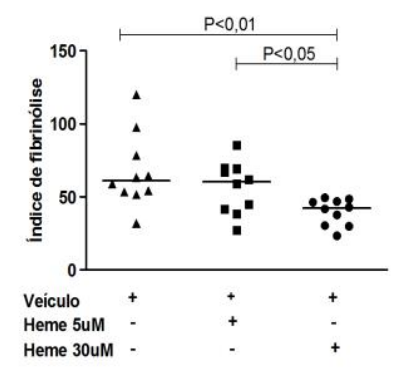

C

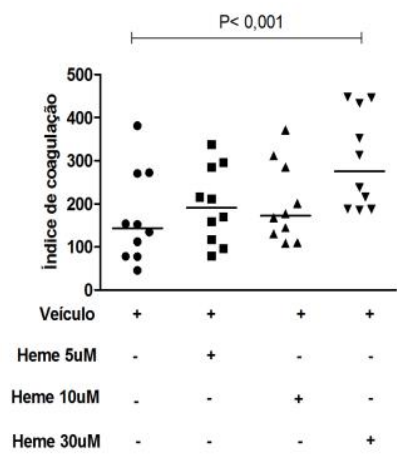

D

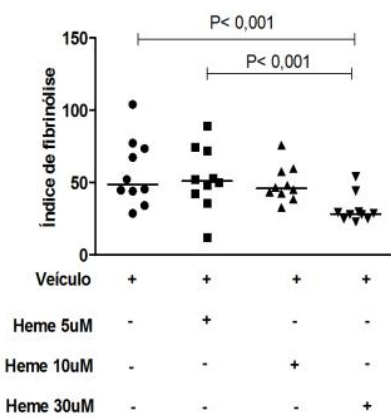

Figura 1- TLC: Índice de coagulação (A) e índice de fibrinólise (B) de amostras de PPP; índice de coagulação (C) e índice de fibrinólise (D) de amostras de ST, mostrando um aumento significativo da ativação da coagulação associada a uma redução do potencial fibrinolítico nas amostras estimuladạis com heme.

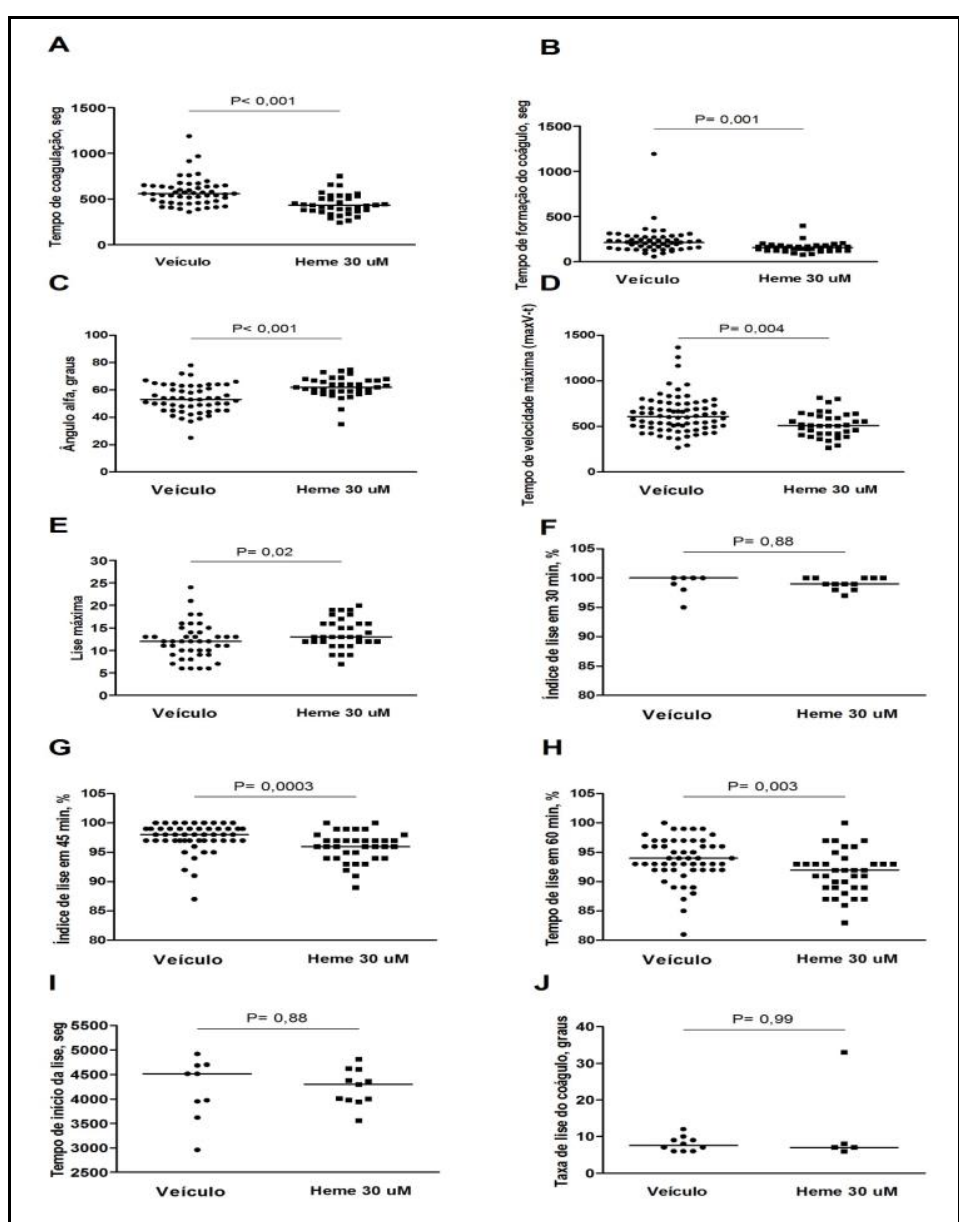

Figura 2 - TEM : As amostras com heme apresentaram uma diminuição nos parâmetros representados acima em relação ao grupo controle (exceto pelo ângulo alfa, ML e CLR). Isso reforça a dualidade da ativação da coagulação e estimulo da fibrinólise na presença do heme.

\section{Conclusões}

A incubação de PPP e ST com heme foi capaz de estimular a coagulação, sugerindo até a formação de coágulos mais firmes, ao mesmo tempo que também pode ser capaz de estimular a fibrinólise. Isso reflete a ideia heterogênea do papel do heme livre na hemostasia.

1. Soares MP, Bozza MT. Red alert: labile heme is an alarmin. 2016

2. Roumenina LT, Rayes J, Lacroix-Desmazes S, Dimitrov JD. Heme: Modulator of Plasma Systems in Hemolytic Diseases. 2016

3. Glueck R, Green D, Cohen I, Ts'ao CH. Hematin: unique effects of hemostasis. Blood. 1983. 4. Morris DL, Dudley MD, Pearson RD. Coagulopathy associated with hematin treatment for acute intermittent porphyria, 1981. 